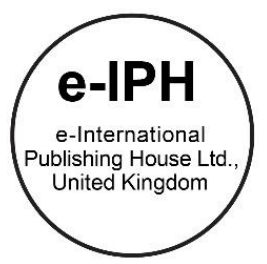

\title{
An Assessment of the Relationship between Urban Air Quality and Environmental Urban Factors in Urban Regeneration Areas
}

\author{
Yakup Egercioglu1*, Nur Sinem Ozcan² \\ ${ }^{1}$ Department of City and Regional Planning, Engineering and Architecture Faculty, Izmir Katip Celebi University, Izmir, 35620, Turkey \\ ${ }^{2}$ Department of City and Regional Planning, Architecture Faculty, Izmir Dokuz Eylul University, Izmir, 35160, Turkey
}

\begin{abstract}
Urban air pollution has been increasing due to ever increasing population, rapid urbanization, industrialization, energy usage, traffic density. The purpose of the study is to examine the relation between urban air quality and urban environmental factors in urban regeneration areas. Two common air polluters (SO2 and PM10) are considered in the study. The data are collected for Cigli district, including the level of air pollutants, the local natural gas service lines and planning decisions for the years between 2007 and 2011. According to the examinations, urban environmental factors and planning decisions affect the urban air quality in urban regeneration areas.

(c) 2016. The Authors. Published for AMER ABRA by e-International Publishing House, Ltd., UK. Peer-review under responsibility of AMER (Association of Malaysian Environment-Behaviour Researchers), ABRA (Association of Behavioural Researchers on Asians) and cE-Bs (Centre for Environment-Behaviour Studies), Faculty of Architecture, Planning \& Surveying, Universiti Teknologi MARA, Malaysia.
\end{abstract}

Keywords: Urban air pollution; urban regeneration; quality of lif; environmental factors Introduction

\section{Introduction}

The term of "quality of life" is a complex concept which can be explained by means of various disciplines and perspectives and also it's not only used to describe some physical features but to describe all the relationship and the dynamics that exist between those physical features. The concept of quality of life defines as a sophisticated issue that can refer to a life enhanced by wholesome food, clean air and water, adequate amount of open spaces, conservation of natural resources, and security (El Din and Shalaby, 2013). In point of socio - economic aspects, it is a broad concept, related to the overall wellbeing in society, interconnecting many different dimension of city life. It does not refer only to the physical resources available to individuals in a neighborhood, but it mainly focuses on enabling people to experience a stress-free and comfortable neighborhood and offer a choice of lifestyle to its residents. Transportation and accessibility of urban spaces and services also affect the urban quality of life, since they can be an obstacle for the capabilities a city can offer (Egercioglu and Ertan, 2014).Actually, urban regeneration is an effective tool for providing safe and habitable environment which has a particularly high natural disaster risk and many more

\footnotetext{
${ }^{*}$ Corresponding author. Tel.: +90-232-329-3535; fax: +90-232-386-0888.

E-mail address: yakup.egercioglu@ikc.edu.tr
}

(c) 2016. The Authors. Published for AMER ABRA by e-International Publishing House, Ltd., UK. Peer-review under responsibility of AMER (Association of Malaysian Environment-Behaviour Researchers), ABRA (Association of Behavioural Researchers on Asians) and cE-Bs (Centre for Environment-Behaviour Studies), Faculty of Architecture, Planning \& Surveying, Universiti Teknologi MARA, Malaysia.

DOI: https://doi.org/10.21834/e-bpj.v1i2.266 
problems and increasing the quality of life for cities. Urban regeneration can be described as "removal of problems ruining the city texture" (Egercioglu and Ertan, 2014). Urban regeneration projects doesn't only contain the many advantages of living in a healthier neighborhood and planned urbanization, but also offers people who were living in unfit conditions to develop a more respectable personality revaluating themselves, and preventing the social excluding. Many descriptions of urban regeneration have been stated in related works. These descriptions vary according to the vision, target, cause, strategy and methods they emphasize. However, no matter how it's described, the general approval is that the urban regeneration is the integrity of strategies and acts to recover the corrupted and collapsed areas of the city, with carefully handling the situation economically, socially, physically and environmentally.

As well as urban regeneration, urban air pollution is a very important issue in terms of not only urban environment but also urban quality of life (Borhan et al., 2013). Urban air pollution has become a global environmental problem throughout the world. It has started with industrialization and has incremented ever since with the increasing usage of fossil fuels. Generally urban air pollution can be explained with population density, population increase, urbanization, industrialization, traffic density, topography and meteorological factors (Ozcan and Cubukcu, 2013). Air pollution is defined in the Tenth Report of the Royal Commission on Environmental Pollution as: "The introduction by man into the environment of substances or energy liable to cause hazard to human health, harm to living resources and ecological systems, damage to structure or amenity or interference with legitimate use of the environment" (Colls and Tiwary, 2010).

This study aims to examine the relation between urban air quality and urban environmental factors in urban regeneration areas. Two common air polluters (sulphur dioxide (SO2) and particulate matter (PM10)) are considered in the study. The data are collected for Cigli district in Izmir, Turkey, including the level of air pollutants, the local natural gas service lines and planning decisions for the years between 2007 and 2011. According to the detailed examinations, urban environmental factors and planning decisions affect the urban air quality in urban regeneration areas. Policy issues are discussed.

\section{Literature}

The term of "quality of life" is influenced by the environment in which people live in the context of places and their characteristics. So any assessment of quality of life should consider the extent to which the necessary conditions for personal satisfaction and happiness are achieved (Marans and Stimson, 2011). Most urban challenges are common in different spatial and cultural communities throughout the world. Different aspects constitute the essential factors of urban quality of life. Better conception of these issues can lead to better solutions and help to more efficiently improve the urban quality of life in cities of different cultures since many of these contexts cannot be generalized (Deffner, 2011). Urban quality of life can be deduced of seven main dimensions which contribute to realize the urban quality of life: environmental urban quality of life, physical urban quality of life, mobility urban quality of life, social urban quality of life, psychological urban quality of life, economical urban quality of life and political urban quality of life. These dimensions are interrelated and dependent on each other (El Din and Shalaby, 2013).

Urban regeneration is a long and hard process that should be under control of social and technical experts like sociologists, architectures and engineers for the most critical places. The management of this process could be under governments which are closest to the public. If local authorities provide financial, legal and technical support, it has been foreseen that there will be successful consequences. This term can be an effective tool for an efficient sub-structural investment of available resources, to control development of long-term plans for city and continuous conversion process of city. It is utilizable to protect genuine quality of the culture and living entities to provide safe and habitable environment for cities which has a particularly high natural disaster risk and many more problems, especially in Turkey (Vural, 2014).

Within the urban regeneration process which aims to provide a secure, organized, and enjoyable city life for residents, three key elements of urban quality of life can be selected to focus on: residential preferences, mobility and accessibility and green spaces. These three elements are actually interlinked and overlapping because urban quality of life is the result of network between these dimensions. In this study, urban regeneration projects of two different examples will be evaluated and compared from the perspective of urban quality of life through these key elements. Also, urban regeneration is an effective tool in terms of providing sustainability and enhances quality of life within the consideration of public participation, advancing equity and improving environment ( $\mathrm{Ng}, 2005)$. In metropolitan cities, it is vital important to be minimized the level of air pollutant in the atmosphere for improving quality of life especially in disadvantaged areas of these cities. Urban air pollution has been increasing 
in urban regeneration areas due to using coal in domestic heating systems instead of natural gas, positioning of one, two or three-floored buildings in only-adjacent, etc (Marans and Stimson, 2011).

\section{Data and Study Area}

The study area has two urban regeneration areas in Cigli district of Izmir City Center. These areas named as Guzeltepe and Sirintepe Urban Regeneration Areas are located on the northeastern part of Cigli district. In these regeneration areas, the dominant land use type is mostly housing with one, two and three-floored buildings. Development plans have been prepared for Guzeltepe and Sirintepe Urban Regeneration Areas by Izmir Metropolitan Municipality in the year 1996, according to the Urban Area Land Use Plan scaled 1/25000. The study area and urban regeneration areas are represented in Figure 1.
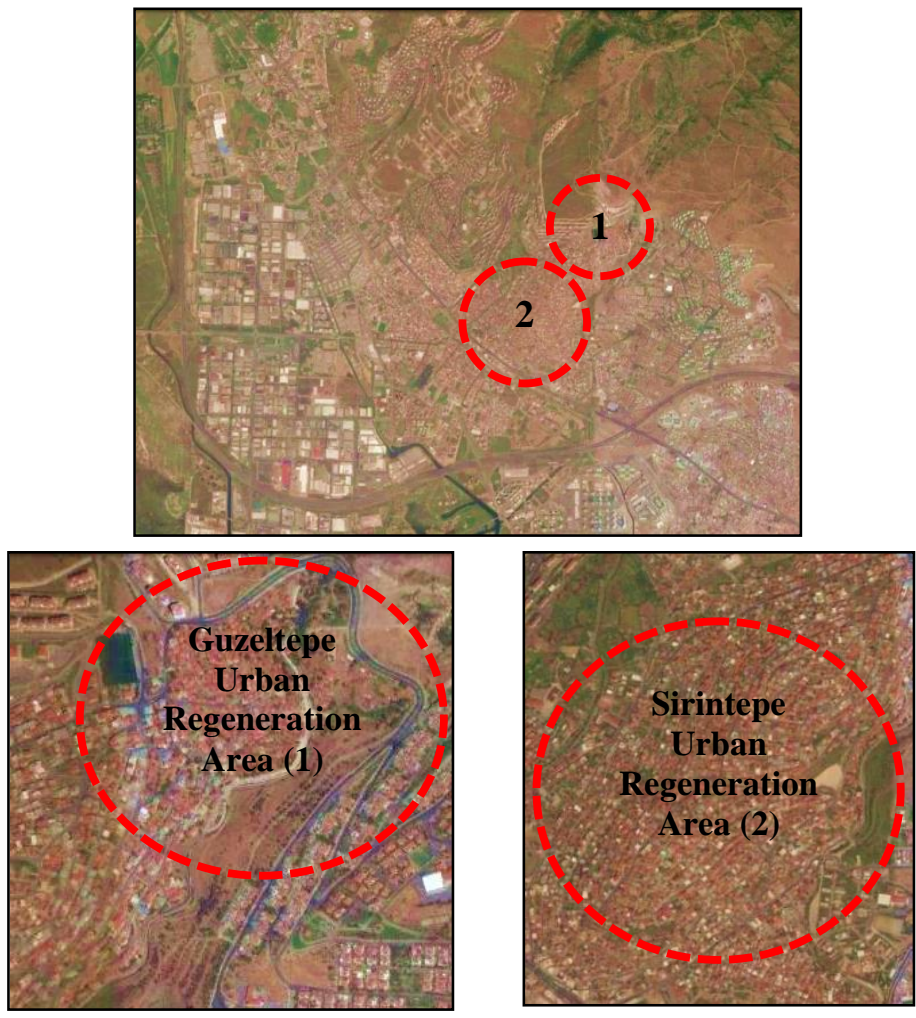

Fig. 1. The study area and urban regeneration areas in Cigli district
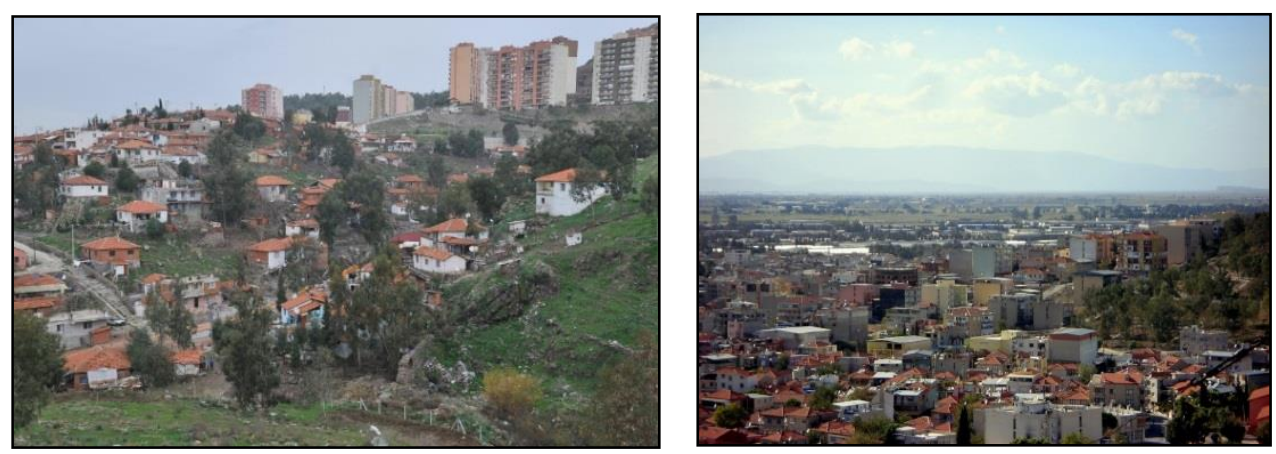
Fig. 2. Site views of urban regeneration areas in Cigli district

The levels of PM10 and SO2 data are available for the years between 2007 and 2011. Data for the level of air quality (PM10 and SO2) at the daily basis are available from the Environmental Health Unit within of the Izmir Metropolitan Municipality. The data for local service lines of natural gas that is preferred as domestic heating system in Cigli district is available from IzmirGAZ Natural Gas Distribution Company for the year 2011. The descriptive statistics at the district level as daily averages for PM10 and SO2 are presented in Table 1 and Table 2. The local service lines of natural gas are presented in Figure 2. The study method is the qualitative and spatial comparison among the non-spatial data and spatial data for urban environmental factors affecting the urban air quality in two urban regeneration areas in Cigli district.

Table 1. The descriptive statistics of the annual average daily PM10 ( $\mu \mathrm{g} / \mathrm{m} 3)$ levels at the district level (2007-2011)

\begin{tabular}{lllll}
\hline Year & Minimum & Maximum & Mean & Std. Deviation \\
\hline 2007 & 0 & 72 & 44.83 & 27.549 \\
2008 & 5 & 29 & 16.83 & 9.283 \\
2009 & 0 & 76 & 45.83 & 25.341 \\
2010 & 36 & 51 & 45.67 & 6.055 \\
2011 & 37 & 71 & 54.83 & 13.805 \\
\hline
\end{tabular}

Table 2. The descriptive statistics of the annual average daily SO2 $(\mu \mathrm{g} / \mathrm{m} 3)$ levels at the district level (2007-2011)

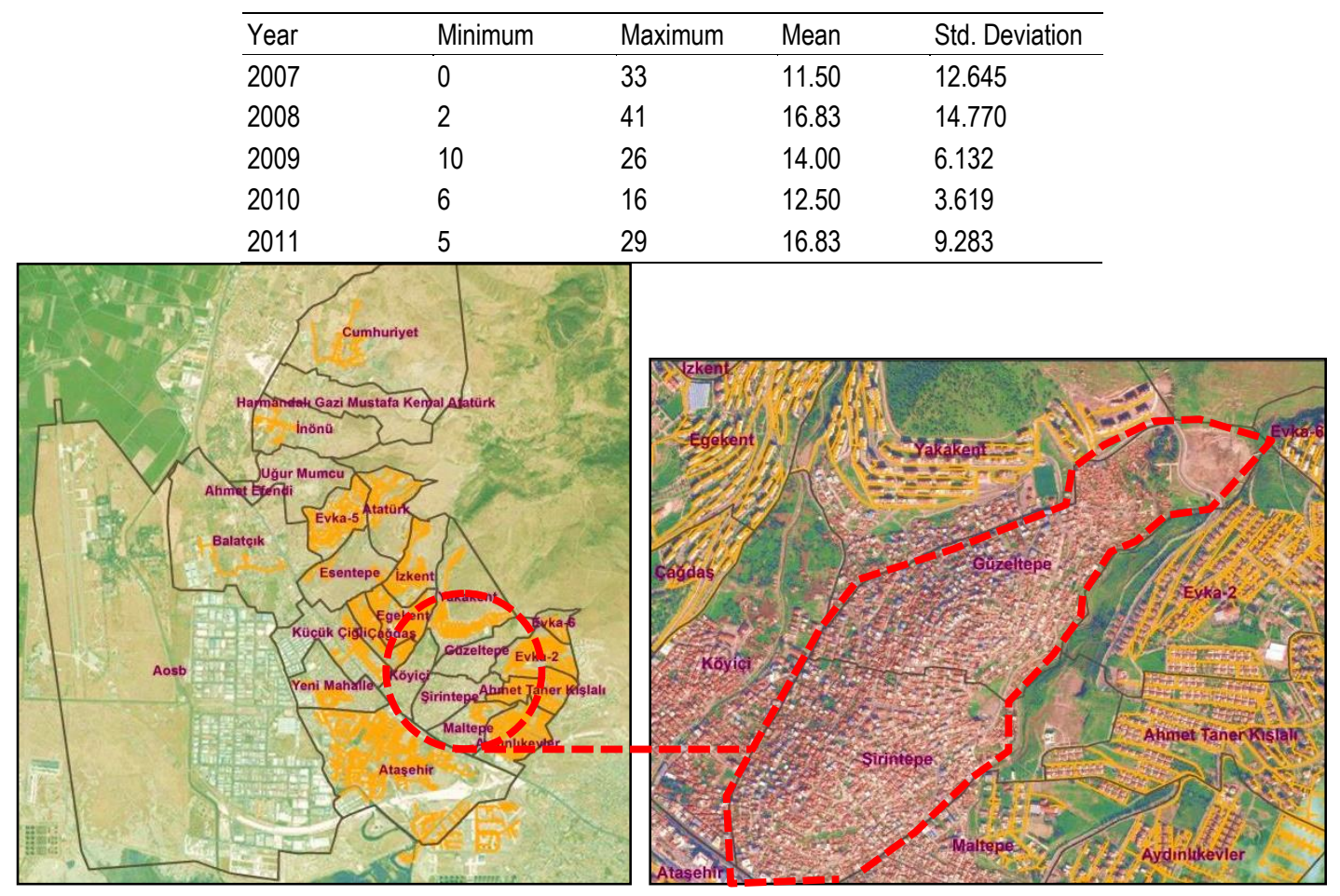

Fig. 3. The local service lines of natural gas in Cigli district and urban regeneration areas 


\section{Results}

This study aims to examine the relation between urban air quality and urban environmental factors in urban regeneration areas. Urban air pollution is measured through the level of two common air polluters: (1) particulate matter (PM10) and (2) sulphur dioxide (SO2).

As known, besides the population growth, the population and building density in the built environment, various factors are significant contributors to increase the level of urban air pollution such as increasing the ownership of automobiles and numbers of vehicles in traffic, the use of fossil fuels in heating and industrial facilities, the use of incorrect and incomplete combustion techniques, the degradation of open and green areas, etc. (Grsic et al., 2014, Sengur et al., 2015). According to the detailed examinations, there exist a military airport (Cigli Military Airport), an industrial area (Izmir Ataturk Organized Industrial Zone), two urban regeneration areas (Guzeltepe and Sirintepe Urban Regeneration Areas) and a highway (Izmir Peripheral Highway) as main sources of air pollutant in Cigli district. These urban environmental factors are presented in Figure 4.

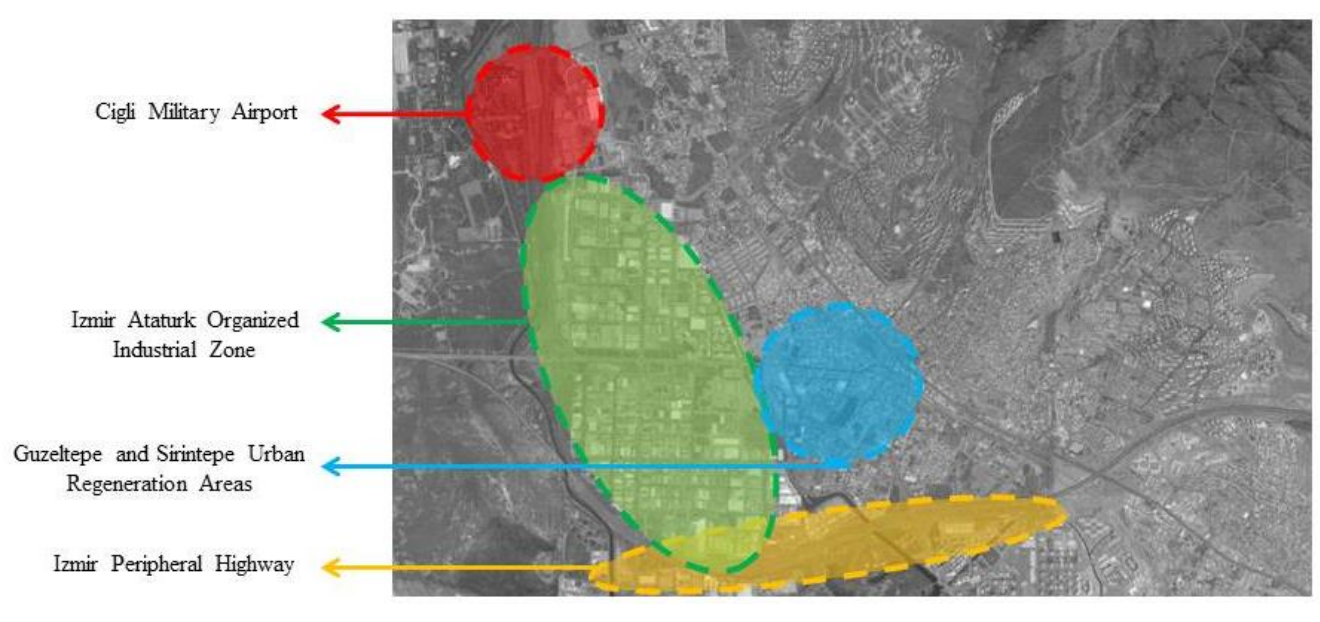

Fig. 4. The urban environmental factors in Cigli district 
Among these environmental factors, two urban regeneration areas are one of the most important factors. Because the levels of urban air pollutants increase dramatically in condition of using coal in domestic heating instead of natural gas, especially in winter months. As seen in Figure 3, there are only two neighborhoods in the Cigli district center that natural gas is not used in domestic heating. Also, the positioning of one, two or three-floored buildings in only-adjacent in these neighborhoods is another significant environmental factor to decrease the air quality.

\section{Conclusion and Recommendations}

This study aims to examine the relation between urban air quality and urban environmental factors in urban regeneration areas. Two common air polluters (sulphur dioxide (SO2) and particulate matter (PM10)) are considered in the study. The data are collected for Cigli district in Izmir, Turkey, including the level of air pollutants, the local natural gas service lines and planning decisions for the years between 2007 and 2011. According to the detailed examinations, urban environmental factors and planning decisions affect the urban air quality in urban regeneration areas. The study method is the qualitative and spatial comparison among the non-spatial data and spatial data for urban environmental factors affecting the urban air quality in two urban regeneration areas in Cigli district.

According to the results, two urban regeneration areas are one of the most important factors in terms of urban air quality among various environmental factors. Because the levels of urban air pollutants increase dramatically in condition of using coal in domestic heating instead of natural gas, especially in winter months. Also, the positioning of buildings in urban regeneration areas is another significant environmental factor to decrease the air quality.

In terms of urban planning discipline, the desire to upgrade the quality of life in a very specific neighborhood or for a selected community is a very important focus. Because rising the quality of life in cities is not any longer and easy matter of physical construction, but the human satisfaction with totally different urban attributes like transportation, quality of public areas, recreational opportunities, land use, etc. It is deducted that the term urban quality of life refers to the objective of forming a sustainable development with reference with reference to an individual's quality of life.

There will be important steps in order to solve the urban air pollution problem and to increase the quality of life for the citizens in urban regeneration areas, such as the dissemination of the usage of natural gas for domestic heating, the emission controls for the reduction of the level of air pollutants because of dense motor vehicle in traffic and monitoring of coal sales, more frequent controls for the measurements for air quality in terms of spatial and time tables, developing plan decisions in consideration of air corridors, the dissemination of open and green areas, encouragement of public transportation and railway transportation type by local governments and realizing studies to minimize carbon emissions and to improve the air quality (Nerriere et al., 2005, Deak et al., 2015, Grsic et al., 2014).

This study has some limitations. Initially, the data used in the study pertains to a limited number of districts in Izmir metropolitan city. A more comprehensive study should consider a larger urban area with a more diverse urban setting. Moreover, the results of the current study reveal that the levels of these two pollutions should be monitored and controlled for improving the quality of life especially in dense urban areas. In addition, the number of monitoring sites is limited in terms of measuring the polluters' concentrations in urban area. Further studies may contain the effects of urban regeneration decisions on the levels of urban pollutants with regard to various air pollutants in more measurement points throughout Izmir city.

\section{References}

Borhan, H., Ahmed, E.M., Hitam, M. (2013). CO2, Quality of life and economic growth in East Asian 8. Journal of ASIAN Behavioural Studies (jABs), Janurary / February 2013: 13-25.

Colls, J. \& Tiwary, A. (2010). Air pollution: Measurement, modelling and mitigation (3rd Edition), Taylor and Francis Group, published by Routledge, Canada, USA.

Deak, G.Y., Tanase, G.S., Daescu, V., Csergo,R., Holban, E., Daescu, A.I., Marinescu, P., Aman, S. (2015). Health-environment relation: A key issue of Romanian environmental protection. Journal of Environmental Protection and Ecology, 16 (1): 304-315. 
Deffner, A. (2011). Defining the quality of urban life: Which factors should be considered?, Proceedings of the 51st ERSA Congress, 785-793.

Egercioglu, Y. \& Ertan, T. (2014). Enhancement of urban life quality in urban regeneration projects: Izmir-Bayraklı urban regeneration project, 1st International Academic Conference Places and Technologies, 230-238.

El Din, H. \& Shalaby, A. (2013). Principles of urban quality of life for a neighborhood. HBRC Journal, 9 (1): 86-92.

Grsic, Z., Dramlic, D., Arbutina, D., Miljevic,N., Dramlic, S., Milutinovic, P., Kaljevic, J., Pavlovic, S., Joksimovic, D. (2014). Representativity of air quality control in limited number of grid points. Journal of Environmental Protection and Ecology, 15 (1): 1-6.

Izmir Metropolitan Municipality (1996). Urban area land use plan, Izmir.

Marans, R. \& Stimson, J. (2011). Investigating quality of urban life. Springer, Dordrecht.

Nerriere,E., Navier,D.Z., Blanchard, O., Momas, I., Ladner, J., Le Moullec, Y., Personnaz, MB., Lameloise, P., Delmas, V., Target, A., Desqueyroux, H. (2005). Can we use fixed ambient air monitors to estimate population long-term exposure to air pollutants? The case of spatial variability in the Genotox ER study.

Environmental Research, 97: 32-42.

Ng, M.K. (2005). Quality of life perceptions and directions for urban regeneration in Hong Kong. Quality-of-life research in Chinese, Western and Global Contexts, 25: 441-465.

Ozcan, N.S. \& Cubukcu, K.M. (2013). Explaining the level of air pollution in Turkey at the county level using employment distribution. Journal of Selçuk University Natural and Applied Science, ICOEST Conf. 2013 (Special Issue-1), 882-892.

Sengur, S., Atabeyoglu, O., Erdogan, N., Erdem, U. (2015). Climate change and effective factors and evaluation of Edremit Coastal areas. Journal of Environmental Protection and Ecology, 16 (2): 764-770.

Vural, A. T. (2014). The role of local retailers' association in the sustainable development of a historical commercial district. Procedia Social and Behavioral Sciences, 168, 87-96. 